\title{
Kinetics and thermodynamics of gossypol extraction from defatted cot- tonseed meal by ethanol
}

\author{
Devesh K. Saxena ${ }^{1}$, Surendra K. Sharma ${ }^{2 *}$, Surinder S. Sambi ${ }^{3}$ \\ ${ }^{1}$ University School of Chemical Technology, Research Scholar, GGS IP University, Dwarka, N. Delhi (India) \\ ${ }^{2}$ University School of Chemical Technology, Asstt. Professor, G G S I P University, Dwarka, N. Delhi \\ ${ }^{3}$ University School of Chemical Technology Professor \& Dean, GGSIP University, Dwarka, N. Delhi \\ "Corresponding author: e-mail: skschem@sify.com
}

\begin{abstract}
Gossypol is polyphenolic aldehyde, a toxic substance naturally present in cotton plant to protect it from insects, pests and diseases. Maximum gossypol is concentrated in the seed. After extraction of oil from the cottonseed, the defatted cottonseed meal which contains both the gossypol and proteinous matter is left behind. A number of attempts have been made using different solvents to extract gossypol from the seeds. However, all these efforts have remained in the realm of academic activity only as none of them could be commercialized. If a pilot plant or commercial scale plant is to be developed then the data on the kinetics and thermodynamics of the extraction process is required. In this study ethanol has been used as the solvent at temperature below $323 \mathrm{~K}$ for removal of gossypol from the defatted seed. This study finds the effects of parameters viz. temperature, solvent to solid ratio (SR) and extraction time on the gossypol extraction efficiency. The data obtained are used to establish the kinetics and thermodynamics of the extraction process.
\end{abstract}

Keywords: gossypol, cottonseed, extraction, food, kinetics, thermodynamics

\section{INTRODUCTION}

Gossypol $\left(\mathrm{C}_{30} \mathrm{H}_{30} \mathrm{O}_{8}\right)$, polyphenolic aldehyde, a yellow pigment present in cotton plant (Gossypium Species) in the form of small discrete structures called pigment glands of size $50-400$ microns $^{1}$ is a highly toxic substance. It is distributed in all parts of the cotton plant and works as a natural defense system for the cotton plant due to its toxicity. Cottonseed is found to contain the maximum gossypol, varying from traces to $6 \%$ depending upon the plant species, variety and environmental factors like climate, soil type and fertilizer ${ }^{2}$. Gossypol is present in the free form while being in the gland but as soon as these glands are ruptured, gossypol forms a complex with the proteinous part of the seed that results in a non toxic bound gossypol ${ }^{3}$.

In spite of its toxicity, gossypol is a valuable substance and has gained importance due to its diversified uses. Starting from 1861 excellent use of gossypol and its brightly colored derivatives have been tried as fabric dyes $^{4}$. Subsequently, gossypol was reported to be one of the strongest antioxidants found in nature. The Japanese reported on its use as a stabilizer for vitamin $\mathrm{A}$ in the products ${ }^{5}$. Researchers in the USSR found gossypol to be an effective antioxidant-stabilizer for PVC, polypropylene, in cement mixtures for road foundations to increase the life of the road and cold resistance and to decrease water absorption. There are a variety of uses of gossypol as an antioxidant in the petroleum and rubber industry, Gossypol has numerous medicinal applications viz. male contraceptive, to promote or assist menstrual flow, to prevent hemorrhaging to stimulate menstrual flow and make child birth easier ${ }^{8}$, as antimicrobial compound and effective in wound healing ${ }^{9}$, for the treatment of scalp infection, dysentery, gonorrhea and to inhibit replication of the HIV-1 virus ${ }^{10}$. Recently, a new use of gossypol as an anticancer drug ${ }^{11}$, pesticide for the control of urban and agricultural pests ${ }^{12}$, has been reported.

Gossypol can be extracted from cottonseed or other parts of the cotton plant by the solvent extraction process. The choice of solvent is based on the solubility of gossypol in the selected solvent, cost and safety. In the case of gossypol extraction from the cottonseed, the selection of solvent is also done on the basis of its working efficiency at low temperature (below 323K) in order to prevent gossypol deactivation by complexing with the protein part (lysine) present in the seed. Considerable work has been reported using solvents ethyl ether ${ }^{13}$, hexane ${ }^{14,15}$, acetone ${ }^{16,17}$, methyl ethyl ketone and phosphoric acid mixture ${ }^{18}$, isopropanol ${ }^{19}$, acetone/hexane mixture $^{20}$, isopropyl alcohol and hexane mixture ${ }^{15}$, water mixture with butanone, trichloroethylene, perchloroeth$y$ lene $^{21}$ for the separation of gossypol from the cotton seed. Junfung $(2010)^{22}$ has reported on the simultaneous extraction of oil and gossypol using the mixture of methanol and hexane.

Recently, the use of alcohols has been gaining importance as the extraction solvent due to two reasons. Firstly, their higher threshold limit in the environment and secondly the residual solvent toxicity in the seed meal after gossypol extraction. Bhowmick (2003) ${ }^{19}$ used isopropanol due to the higher solvency of gossypol in it. In the alcohol series, ethanol is the safest solvent and is placed in the category of GRAS (generally recognized as safe). Hron et al. (1994) ${ }^{23}$ have reported the extraction of at least $50 \%$ of total gossypol from the cottonseed at low temperature (298-308K). Further, it was reported that at higher temperature the extraction of gossypol was not possible as it combines with protein present in the cottonseed. No detailed data regarding gossypol extraction from cottonseed with ethanol has been reported. The efficiency of gossypol extraction depends upon the preparation of the seed prior to the extraction. These parameters include particle size, temperature, mode of operation (batch or continuous and co-current or counter-current operations) and other parameters like temperature, solvent to solid ratio, extraction time. 
The present study involves the use of pure ethanol for the extraction of gossypol from the cottonseed at temperature less than $323 \mathrm{~K}$ to explore the possibility of improving the extraction efficiency of gossypol. This may also have added advantage of getting a good quality of cake suitable for food/ feed. This paper discusses the effect of parameters viz. temperature, solvent to solid ratio and extraction time on extraction efficiency of gossypol. The data obtained are used to establish the kinetics and thermodynamics of the extraction process.

\section{MATERIALS AND METHODS:}

\section{Cotton seed}

Acid delinted cottonseed (Gossypium Hirsutum) variety P8-6, procured from Indian Agricultural Research Institute, Pusa, New Delhi was used in this study. The seeds were dehulled and ground in the laboratory with the help of a mixer grinder. The dehulled seeds were dried in the vacuum oven at $318 \mathrm{~K}$ and segregated with $14 \mathrm{mesh}$ standard sieve to have avg. particle size of $0.60 \mathrm{~mm}$. The dehulled seeds had fat content $36.875 \%$ on the moisture free basis.

\section{Solvents}

The laboratory reagent grade hexane and ethanol supplied by Fisher, India were used to de-fat the seeds and gossypol extraction respectively. Ethanol was redistilled before putting into actual use.

\section{Oil extraction}

The purpose of this step was to de-fat the seeds. The seed in the batch of $50 \mathrm{gm}$ were mixed with $500 \mathrm{ml} \mathrm{N}$ Hexane using a sealed air tight container and kept in a shaking incubator maintained at $308 \mathrm{~K}$ for 60 minutes to extract oil. The supernatant liquid was separated from the solid seed and tested for oil content as per method described in literature ${ }^{24}$. The procedure was repeated seven times for maximum oil removal. The total extraction of oil by the end of $7^{\text {th }}$ extraction was $99.7 \%$. After the $7^{\text {th }}$ extraction the solid seeds were kept in the vacuum oven at $308 \mathrm{~K}, 700 \mathrm{mmHg}$ vacuum overnight for the removal of N-hexane. Gossypol in the defatted seed was found to be $1.95 \%$. The defatted seeds (DFS) were used for gossypol extraction.

\section{Gossypol testing}

The total gossypol content in the seed sample was determined according to the standard method described in Appendix A \& B of IS: 4874-1968 of Bureau of Indian Standards using ECIL make double beam UV-Visible spectrophotometer, model UV5704SS at 440nm (IS: 4874-1968). The method involves development of the colored complex of gossypol with neutralized 3-amino1-propanol in dimethyl formamide.

\section{Batch studies}

The objective of the batch study was to find the global kinetic of extraction and to analyze the influences of the operating parameters. The weighed quantity of the DFS samples were taken in six $30 \mathrm{ml}$ capacity bottles along with the required quantity of the solvent and kept at a desired constant temperature, in shaking incubator to attain uniform temperature. The measured quantity of the solvent was poured in the bottles containing DFS for the extraction of gossypol. The bottles were closed air tight and kept immediately in the shaking incubator. The study was conducted for a period of three hours and the samples were drawn after a period of 5, 10, 30, 60, 120 and 180 minutes. One bottle was taken out after the specified time period. The solid was separated by filtration under vacuum, dried and tested for residual gossypol content in the DFS. Gossypol concentration in liquid was determined by mass balance using the following relation

$C_{t}=\frac{\left(C_{o}-C_{s}\right) F}{V}$

Where $C_{t}=$ gossypol concentration in ethanol at any time $\mathrm{t}(\mathrm{mg} / \mathrm{ml})$

$C_{o}=$ gossypol content in DFS initially $(\mathrm{mg} / \mathrm{mg})$

$C_{s}=$ gossypol content in DFS at any time $\mathrm{t}(\mathrm{mg} / \mathrm{mg})$

$F=$ wt of solid sample taken for extraction $(\mathrm{mg})$

$V=$ volume of ethanol used for extraction $(\mathrm{ml})$

\section{RESULTS AND DISCUSSION}

\section{Effect of solvent to solid ratio}

Three solid to the solvent ratios (SR) i.e. 5, 10 and 15 were tried for 3.0 hours during the study at temperatures of 288, 298, 308 and $318 \mathrm{~K}$. The data are shown in Figure 1. It may be seen from Figure 1 that increase in $\mathrm{SR}$ increased the amount of the gossypol extracted. The extraction of gossypol at the SR: 5 was $36.45 \%$, and at SR: 15 extraction of was $55.08 \%$. The lower gossypol extraction at the SR: 5 can be explained by the fact that the solubility of gossypol in ethanol may restrict the gossypol extraction from the DFS near the saturation point of oil in ethanol.

\section{Effect of extraction temperature}

The increase in temperature has a direct effect on the amount of gossypol extracted as is shown in Figure 1. It may be seen from Figure 1 that the amount of gossypol extracted increased from $19.41 \%$ to $42.19 \%$ by increasing the extraction temperature from $288 \mathrm{~K}$ to $318 \mathrm{~K}$ at a Solvent ratio of 5 by extraction with ethanol. With the SR: 10 the maximum extraction at 288 and $318 \mathrm{~K}$ were $25.22 \%$ and $55.44 \%$. With the SR: 15 the maximum extraction at 288 and $318 \mathrm{~K}$ were $34.98 \%$ and $61.55 \%$. This increase may be due to increase in gossypol solubility

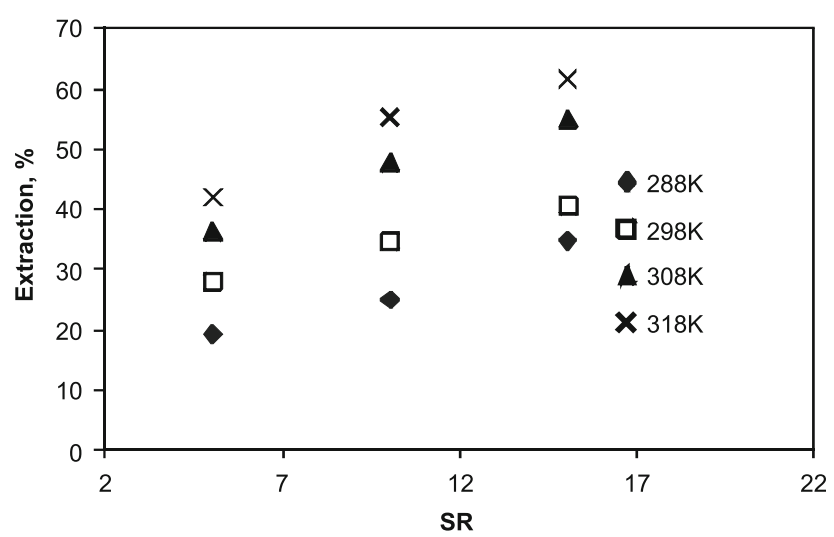

Figure 1. Effect of SR on Gossypol Extraction at Various Temperatures from DFS 
in the ethanol at a higher temperature and a decrease in viscosity of the solution resulting in lower diffusion resistance in the pores of the DFS.

\section{Effect of extraction time}

Time is an important parameter for any extraction process for the optimum utilization of the process plant and machinery. Thus the effect of the extraction time was studied and the results are shown in Figure: 2 for SR: 15 at various temperatures. It can be seen from Figure: 2 that the extraction rate was rapid at the beginning of the period and became very slow at the end for all the temperatures. It was found that more than $90 \%$ of the maximum gossypol was extracted in about 1.0 hour at a particular temperature. The initial fast extraction of alcohol soluble gossypol can be attributed to the dissolution of freely available glands and the driving force of the fresh solvent. Later the slow rate can be attributed to a slow diffusion of gossypol from the solid surface surrounding the gossypol glands and also reduction in the driving force of the solvent due to equilibrium or the solubility limit of gossypol at a particular temperature.

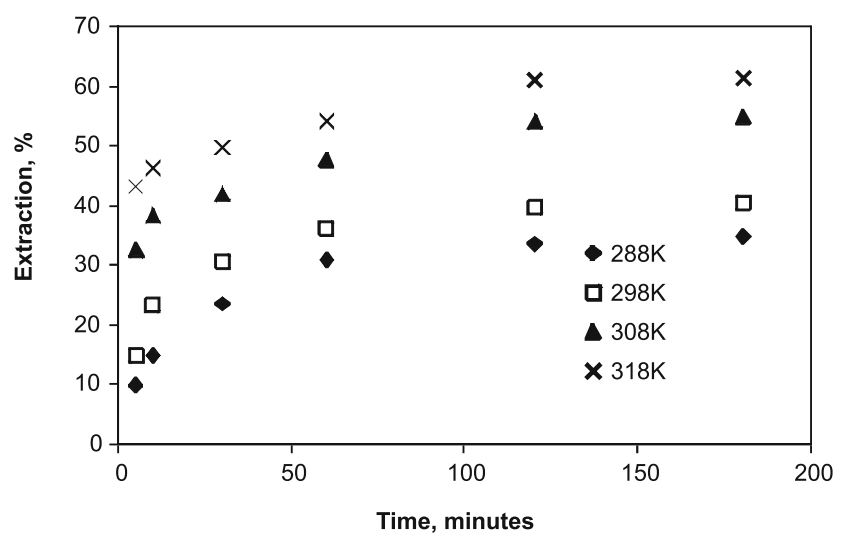

Figure 2. Effect of Extraction Time on Gossypol Extraction from DFS

\section{KINETICS OF EXTRACTION}

Various studies that describe the mechanism and kinetics of the extraction processes have been reported. A second order reaction kinetics for the solid-liquid extraction process has been proposed by most of the

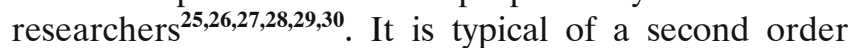
process to take place in two stages. First, the major part of the solute gets extracted quickly because of the dissolution and scrubbing of the surface solute caused by a higher driving force of the fresh solvent and in the next stage where the extraction rate is slowed down by low diffusion of the remainder solute. The rate of the dissolution of the solute into the solution can be described by the following second order rate equation: $\frac{d C_{t}}{d t}=k\left(C_{e}-C_{t}\right)^{2}$

Now considering the initial condition at $t=0, C_{t}=0$, the integrated second-order rate equation for extraction can be written as

$C_{t}=\frac{C_{e}^{2} k t}{1+C_{e} k t}$

The extraction rate Equation (2) can be rearranged and written as follows
$\frac{C_{t}}{t}=\frac{k C_{e}^{2}}{1+C_{e} k t}$

Now, when $t \rightarrow 0$, the LHS of Equation (3) will be initial extraction rate, $E_{i}$, and denominator of RHS will approach, thus Equation (3) reduces to $E_{i}=k C_{e}^{2}$

Thus Equation (3) and Equation (4) after rearrangement yield the following linear form

$\frac{t}{C_{t}}=\frac{1}{E_{i}}+\frac{t}{C_{e}}$

The initial extraction rate, $E_{i}$, the concentration of solute in the solution at equilibrium, Ce and the second order extraction constant, $k$, can be calculated from the experimental data by plotting $t / C_{t}$ vs. $t$.

The experimental data upon regression yielded kinetics coefficient, $\mathrm{k}$. The estimated results of gossypol extraction by ethanol from DSM at SR: 5 to 15 and temperature from 288 to $318 \mathrm{~K}$ are given in Table 1 . The results show that for all the cases the value of the regression coefficient $\left(\mathrm{R}^{2}\right)$ lies between $0.978-0.999$. This indicates that the data are well described by the second order kinetics. The agreement of the second order extraction model with the experimental results confirm the assumptions that initially there is intense dissolution and scrubbing of gossypol from the freely available glands in which maximum leaching takes place. The later slower stage occurs due to high diffusion resistance offered by the solid surrounding the glands and the external diffusion, which is related to the solubility of remainder gossypol in solvent. The variation of the initial extraction rate, $E i$, is given in Table 1

It can be seen from Table 1 that the initial rate of extraction is not appreciably affected by SR but is largely affected by temperature and increases with an increase in temperature at all SR. The average value of the initial extraction rate was found to vary from 0.029 to $0.211 \mathrm{mg} / \mathrm{ml}-\mathrm{min}$ as temperature increased from $288 \mathrm{~K}$ to $318 \mathrm{~K}$. For $E i$ and $C e$ Table Curve 3D v 4.0 software was used to describe the dependency of Ei and Ce on temperature(T) and SR(S). The kinetics results were further used to determine the coefficient of empirical Equations. The following equations were found to be the most appropriate for the calculation of $\mathrm{Ei}$ and $\mathrm{Ce}$.

$\mathrm{Ei}=\mathrm{a}+\mathrm{bT}+\mathrm{c} \mathrm{T}^{2}$

$\mathrm{Ce}=\mathrm{e}+\mathrm{f} \mathrm{S}+\mathrm{g} \mathrm{T}+\mathrm{h} \mathrm{S}^{2}+\mathrm{i} \mathrm{T}^{2}+\mathrm{j} \mathrm{S} \mathrm{T}$

The values of the coefficients of empirical equations (6) and (7) obtained from the software are reported on in Table 2.

It was found that the empirical equation (6) and (7)

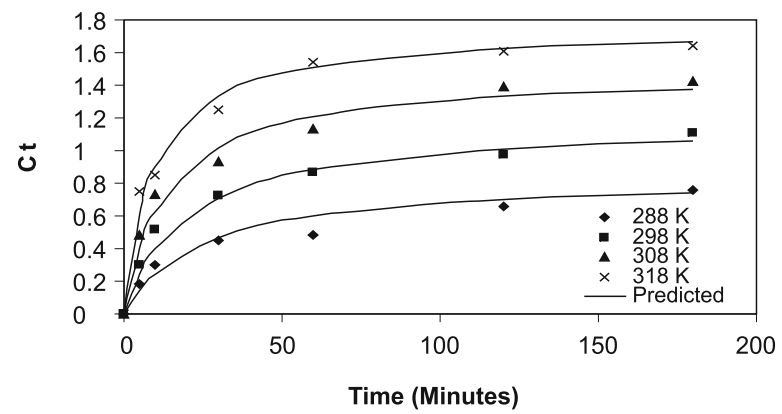

Figure 3. Predicted kinetics of gossypol extraction from DFS by ethanol at SR:5 
Table 1. The kinetics parameters of gossypol extraction from DFS by ethanol

\begin{tabular}{|c|c|c|c|c|c|c|}
\hline Solvent & $S R$ & Temp, K & $\mathrm{Ce}$ & $E i$ & $k$ & $R^{2}$ \\
\hline \multirow[t]{12}{*}{ Ethanol } & 5 & 288 & 0.824 & 0.033 & 0.049 & 0.978 \\
\hline & 5 & 298 & 1.170 & 0.069 & 0.051 & 0.994 \\
\hline & 5 & 308 & 1.531 & 0.105 & 0.045 & 0.996 \\
\hline & 5 & 318 & 1.728 & 0.193 & 0.065 & 0.999 \\
\hline & 10 & 288 & 0.538 & 0.029 & 0.099 & 0.989 \\
\hline & 10 & 298 & 0.711 & 0.076 & 0.151 & 0.999 \\
\hline & 10 & 308 & 0.975 & 0.092 & 0.097 & 0.997 \\
\hline & 10 & 318 & 1.108 & 0.211 & 0.172 & 0.999 \\
\hline & 15 & 288 & 0.494 & 0.032 & 0.133 & 0.999 \\
\hline & 15 & 298 & 0.558 & 0.057 & 0.182 & 0.999 \\
\hline & 15 & 308 & 0.740 & 0.105 & 0.191 & 0.998 \\
\hline & 15 & 318 & 0.821 & 0.153 & 0.226 & 0.998 \\
\hline
\end{tabular}

Table 2. The values of the constants for the empirical relations of $\mathrm{Ei}$ and $\mathrm{Ce}$ for gossypol extraction

\begin{tabular}{|l|l|l|}
\hline S. No & Equation & Constant Values \\
\hline 1. & Eq. 6 (Ei) & $\mathrm{a}=9.82365$, \\
& & $\mathrm{b}=(-) 0.06927$, \\
& & $\mathrm{c}=0.0001225$ \\
& & $\mathrm{e}=(-) 23.1067$ \\
& Eq. 7 (Ce) & $\mathrm{f}=0.39253$ \\
& & $\mathrm{~g}=0.12666$ \\
& & $\mathrm{~h}=0.00601$ \\
& & $\mathrm{i}=(-) 0.00014333$ \\
& & $\mathrm{j}=(-) 0.00191$ \\
\hline
\end{tabular}

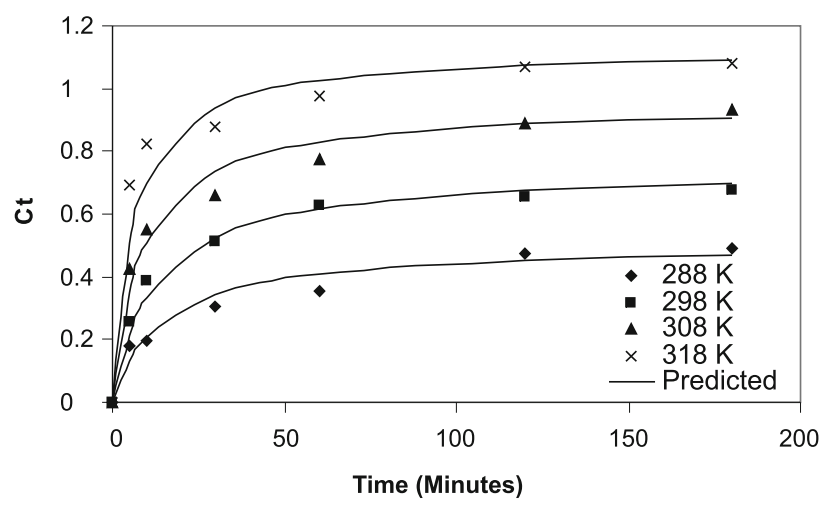

Figure 4. Predicted kinetics of gossypol extraction from DFS by ethanol at SR:10

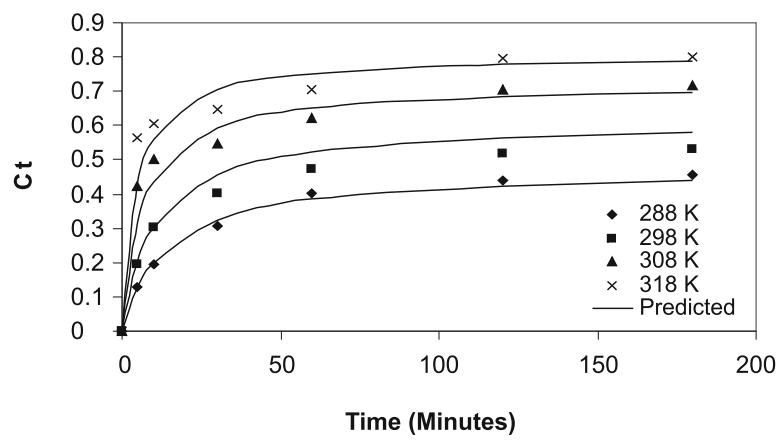

Figure 5. Predicted kinetics of gossypol extraction from DFS by ethanol at SR:15

are sufficient to describe the dependencies of $E i$ and $\mathrm{Ce}$ on temperature and SR. The kinetics of gossypol extraction was used to predict gossypol extraction by ethanol from DFS. These predicted results for SR: 5, 10 and 15 are shown in Figures: 3 to 5. These figures show that the predicted results are in good agreement with the experimental data.

\section{THERMODYNAMICS}

Thermodynamic considerations of the extraction process are necessary to conclude whether the process is spontaneous or not. The Gibbs free energy change $\left(\Delta G^{\circ}\right)$ is an indication of the spontaneity of a chemical reaction and therefore is an important criterion for spontaneity. Reactions occur spontaneously at a given temperature if $\Delta G^{\mathrm{o}}$ is a negative quantity. The Gibbs free energy $\left(\Delta G^{\circ}\right)$, enthalpy change $\left(\Delta H^{\circ}\right)$ and entropy change $\left(\Delta S^{\circ}\right)$ are calculated using the following equations $K_{e}=\frac{C_{e}}{C_{s e}}$

$\Delta G^{o}=-R T \ln K_{e}$

$\ln K_{e}=-\frac{\Delta H^{o}}{R T}+\frac{\Delta S^{o}}{R}$

Where $C$ is a concentration of Gossypol in the solid phase at equilibrium and could be obtained by material balance using Equation 1. $R$ is the ideal gas constant (8.314 $\left.\mathrm{J} \mathrm{mol}^{-1} \mathrm{~K}^{-1}\right)$, and $T$ is the temperature $(\mathrm{K})$. Eq. 11 is a Van't Hoff relation and Plot of $\ln K_{\mathrm{e}}$ vs $1 / T$ is used to find the values of $\Delta H^{\circ}$ and $\Delta S^{\circ}$ from the slope and the intercept. $\Delta G^{\mathrm{o}}$ and $\Delta H^{\mathrm{o}}$ are in $\mathrm{J} / \mathrm{mol}, \Delta S^{\mathrm{o}}$ is in $\mathrm{J} / \mathrm{mol} \mathrm{K}$.

The values of $K_{e}, \Delta G^{\mathrm{o}}, \Delta H^{\mathrm{o}}$ and $\Delta S^{\mathrm{o}}$ for the extraction of Gossypol using ethanol were calculated using Eqs. (9) to (11) are given in Tables 2. The values of $\Delta G^{\mathrm{o}}$ calculated were found negative for gossypol extraction from the defatted cottonseed at all solid to solvent ratio and decreases from -8376.47 to $-12125.9 \mathrm{~J} / \mathrm{mol}$ at $\mathrm{SR}=5$ , from -7557.17 to $-11626.8 \mathrm{~J} / \mathrm{mol}$ at $\mathrm{SR}=10$ and from -7727.85 to $-11253.8 \mathrm{~J} / \mathrm{mol}$ at $\mathrm{SR}=15$ with increase in temperature from 288 to $318 \mathrm{~K}$. The negative value for the Gibbs free energy for gossypol extraction from the defatted cottonseed confirms that the process is feasible and spontaneous and that the degree of spontaneity of the extraction increases with increasing the temperature as $\Delta G^{\circ}$ becomes more negative. The decrease in the negative value of $\Delta G^{\circ}$ with an increase in temperature 
Table 3. Thermodynamics parameters

\begin{tabular}{|c|c|c|c|c|c|}
\hline SR & Temp, K & $K_{e}$ & $\begin{array}{c}\Delta G^{\circ} \\
(\mathrm{J} / \mathrm{mol})\end{array}$ & $\begin{array}{c}\Delta H^{\circ} \\
(\mathrm{J} / \mathrm{mol})\end{array}$ & $\begin{array}{c}\Delta S^{\circ} \\
(\mathrm{J} / \mathrm{mol} \mathrm{K})\end{array}$ \\
\hline 5 & 288 & 33.05962 & -8376.47 & \multirow[t]{4}{*}{28093.83} & \multirow[t]{4}{*}{127.00} \\
\hline 5 & 298 & 52.88579 & -9831.34 & & \\
\hline 5 & 308 & 79.72246 & -11212.2 & & \\
\hline 5 & 318 & 98.14526 & -12125.9 & & \\
\hline 10 & 288 & 23.4799 & -7557.17 & \multirow[t]{4}{*}{32630.78} & \multirow[t]{4}{*}{139.53} \\
\hline 10 & 298 & 35.445 & -8839.93 & & \\
\hline 10 & 308 & 61.74106 & -10557.7 & & \\
\hline 10 & 318 & 81.26012 & -11626.8 & & \\
\hline 15 & 288 & 25.2146 & -7727.85 & \multirow[t]{4}{*}{27749.64} & \multirow[t]{4}{*}{122.70} \\
\hline 15 & 298 & 30.89735 & -8499.73 & & \\
\hline 15 & 308 & 54.28495 & -10228.1 & & \\
\hline 15 & 318 & 70.56913 & -11253.8 & & \\
\hline
\end{tabular}

indicates that the gossypol extraction from the cottonseed becomes more favorable at higher temperatures. The values of $\Delta H^{\mathrm{o}}$ calculated from the plot of $\operatorname{lnKe}$ versus $1 / T$ (Table 3 ) were in the range 27749.64 to $32630.78 \mathrm{~J} /$ mol. The value of $\Delta H^{\circ}$ was positive, indicating that the extraction is endothermic requires energy during the process. The positive value of entropy indicates that the process is irreversible.

\section{CONCLUSION}

The results indicate that about $61.55 \%$ gossypol can be removed by pure ethanol from the defatted cottonseed meal at $318 \mathrm{~K}$, with the solvent to solid ratio of 15 and PS: $0.6 \mathrm{~mm}$ After the removal of the gossypol from the cottonseed, the seed meal can be mixed in the cattle feed in much higher proportions. The cottonseed meal can also be used in food preparations by blending with cereals in such proportions that the free gossypol content is restricted within the safe limit of $450 \mathrm{ppm}$ as per FDA. The removed gossypol can be further concentrated to fetch higher price due to its diversified use in medicinal, insecticide, pharmaceutical and plastic industry. The experimental data were analysed to understand the kinetics and thermodynamics of the gossypol extraction process so that a commercial scale unit may be developed. The results indicate that the extraction process follows the second order kinetics and the extraction process is endothermic, irreversible and spontaneous.

\section{LITERATURE CITED}

1. Spadaro, J.J., Persell, R.M., Murphey, C.H. Jr., Vix, H.L.E., McCourtney, E.J., Hecker, J.L., Pollard, E.F. \& Gastrock, E.A., (1948). Pilot-plant fractionation of cottonseed I. Disintegration of cottonseed meats. J. American Oil Chemists' Society. 25(), 345-53. DOI: 10.1007/BF02593275.

2. Angela Sotelo, Hortensia Villavicencio \& Irene Montalvo (2005). Gossypol content on leaves and seeds some wild Malvaceae species. Afr. J. Traditional, Complementary and Alternative Medicines. 2(1):4-12.

3. Arnold, L.K. (1955). The Reduction of Free Gossypol in Cottonseed Flakes during Solvent Extraction. J. American Oil
Chemists' Society, 32(3), 151-152, DOI: 10.1007/BF02640325

4. Boatner, C.H. \& Hall, C.M., (1944). Preparation of gossypol from cottonseed pigment glands. Oil \& Soap. 25 (7), 233-236, DOI: $10.1007 / \mathrm{BF} 02593470$.

5. Adams, R., Geissman, T.A. \& Edwards, J.D., (1960). Gossypol, a Pigment of Cottonseed. Chem. Rev. 60, 555-57. DOI: $10.1021 /$ cr60208a002.

6. Royce, H.D. (1933). Stability tests on fats containing oxidation accelerators and inhibitors. Oil \& Soap. 10(7), 123-125. DOI: $10.1007 / \mathrm{BF} 02638133$.

7. Hron R.J. et. al. (1987Sept.). The potential commercial aspects of gossypol. J. American Oil Chemists' Society, 64(9),1315-1319, DOI: 10.1007/BF02540789.

8. Wayne, E.S. J. Pharm. 44:289 (1872 Sept.) cited in the paper Hron R.J. et. al. (1987). The potential commercial aspects of gossypol. Jr. of American Oil Chemists' Society. 64(9), 1315-1319, DOI: 10.1007/BF02540789.

9. Vadehra, D.V.; Kalla, N.R.; Saxena, M.; Hashia, R.; Kaur, Parjit; Gupta, L.K.(1985). Antimicrobial activity of gossypol acetic acid, IRCS Medical Science, 13(1), 10-11.

10. Gossypol-wikipedia.the free encyclopedia. http://en.wikipedia.org/wiki/gossypol.

11. Strax, J. (2004). Cottonseed drug boosts cancer treatment in mice. www.psa- rising.com/med/chemo/gossypol1004.htm.

12. Rojas, Maria, G., Morales-ramos, Juan, A.,Wan \& Peter, J. (2004). Use of gossypol and related terpenes for control of urban and agricultural pests, US Patent No. 6773727.

13. Smith, F.H. \& Halverson, J.O. (1946 Nov.). Extraction \& Purification of gossypol from cottonseed meats Oil \& Soap, 361-363. DOI: 10.1007/BF02641665.

14. Chernenko, T.V. et. al. (1980). Extraction of Gossypol. Translated from Khimiya Prirodnykh Soedinenii, No.2. 157-160.

15. Rama, E.H. \& Narasinga Rao, M.S.. (1984 July). Gossypol removal and functional properties of protein produced by extraction of glanded cottonseed with different solvents. $J$. Food Science Vol. 49. 1057-1060. DOI: 10.1111/j.1365-2621.1984. tb10391.x.

16. Yuan, J.R .(1984Feb.). Methods of extraction and purification of gossypol. Shengzhi Yu Biyun, 4(1), 61-62.

17. Hron, R.J.Sr. \& Kuk, M.S.(1989). Acetone Extracted Cottonseed Meals without catty odor. J. Food Science. 54(4), 1088-89. DOI: 10.1111/j.1365-621.1989.tb07954.x.

18. Walter, A. Pons, J.R., Joseph Pominski, King, W.H., Harris, James A. \& Hopper, T.H., (1959). Recovery of Gossypol from Cottonseed Gums. J. American Oil Chemists' Society, 36(8), 328-332. DOI: 10.1007/BF02640046 
19. Bhowmick, D.N. \& Rebello, D. (2003), Sponsored project: Improved utilization of cottonseed meal by isopropanol extraction, Deptt. of Oils, University Institute of Chemical Technology, Matunga, Mumbai.

20. Kuk, M., Tetlow, R. \& Dowd, M., (2005). Cottonseed extraction with mixtures of Acetone \& Hexane" Agricultural Research Service, USDA Research Project: New and Expanded Uses of Oilseed Products \& By products. www.ars.usda.gov/ research/publication.

21. Dachery, J.M. et. al. (1952). Removal of gossypol from cottonseed by solvent extraction procedures. J. American Oil Chemists' Society, 29(8), 339-341. DOI: 10.1007/BF02639814.

22. Junfeng, Q., Zhi, Y. \& Haixian, S. (2010). Cogeneration bio diesel and non toxic cottonseed meal from cottonseed processed by two phase solvent extraction. Energy Conversion and Management, 51(12), 2750-2756 DOI:10.1016/j.enconman.2010.06.011.

23. Hron, R.J et. al. (1994) Ethanol extraction of Oil, Gossypol and Aflatoxin from cottonseed. J. American Oil Chemists' Society, 71(4), 417-421, DOI: 10.1007/ BF02540523.

24. Saxena, D.K., Sharma, S.K. \& Sambi, S.S.(2011), Kinetics and Thermodynamics of cottonseed oil extraction., Grasas y Aceites, 62 (2), 198-205. DOI: 10.3989/gya.090210.

25. Meziane, S., Kadi, H. \& Lamrous, O. (2006). Kinetic study of oil extraction from olive foot cake. Grasas y Aceites, 57(2): 175-179. DOI:10.3989/gya.2006.v57.i2.

26. Meziane, S. \& Kadi, H., (2008). Kinetics and thermodynamics of oil extraction from olive cake. J. American Oil Chemists' Society. 85(4): 391-396. DOI: 10.1007/s11746-008-1205-2.

27. Maria, Y.L. et.al. (2008). Extraction of neem oil using n-hexane and ethanol: studies on oil quality, kinetic \& thermodynamics. ARPN J. Eng. Appl. Sci.3 (3), 49-54.

28. Rakotondramasy, R.L., Havet, J.L., Porte, C. \& Fauduet, H., (2007) . Solid-liquid extraction of protopine from fumaria officinalis L-Analysis determination, kinetic reaction and model building., Sep.Purification Technol. 54(2), 253-261. DOI:10.1016/j.seppur.2006.09.015.

29. Sepidar, S., Zurina, Z.A., Yunus, R. \& Muhammad, A. (2009). Extraction of Oil from Jatropha Seeds-Optimization and Kinetics, Am. J. Applied Science. 6(7), 1390-1395. DOI:10.3844/ ajassp.2009.1390.1395.

30. Wenjuan, Q., Zhongli, P. \& Haile, M., (2010). Extraction modeling and activities of antioxidants from pomegranate marc, J. Food Eng. 99, 16-23. DOI:10.1016/j.jfoodeng.2010.01.020. 